Images in...

\title{
Cepacia syndrome in a cystic fibrosis patient colonised with Burkholderia multivorans
}

Irfan Shafiq, ${ }^{1}$ Marry P Carroll, ${ }^{2}$ Julia A Nightingale, ${ }^{2}$ Thomas V W Daniels ${ }^{2}$

${ }^{1}$ Department of Respiratory medicine, Royal Bournemouth Hospital, Bournemouth, Dorset, UK;

${ }^{2}$ Adult Cystic Fibrosis unit, Southampton General Hospital, Southampton, Hampshire, UK

Correspondence to Irfan Shafiq, irfanshafiq@gmail.com

\section{DESCRIPTION}

The authors present the case of an 18-year-old girlwith cystic fibrosis. Her genotype was F508/N1303K. She had sputum colonisation by Pseudomonas aeruginosa and Staphylococcus aureus and since 2006, she also had Burkholderia cepacia in sputum, which was typed as genomovar II (Burkholderia multivorans). Her lung function had remained stable but low over the last few years despite complex psychosocial problems and issues with treatment compliance. She deteriorated at the end of May 2010 and was admitted with right upper lobe cavitating pneumonia. After 6 weeks of

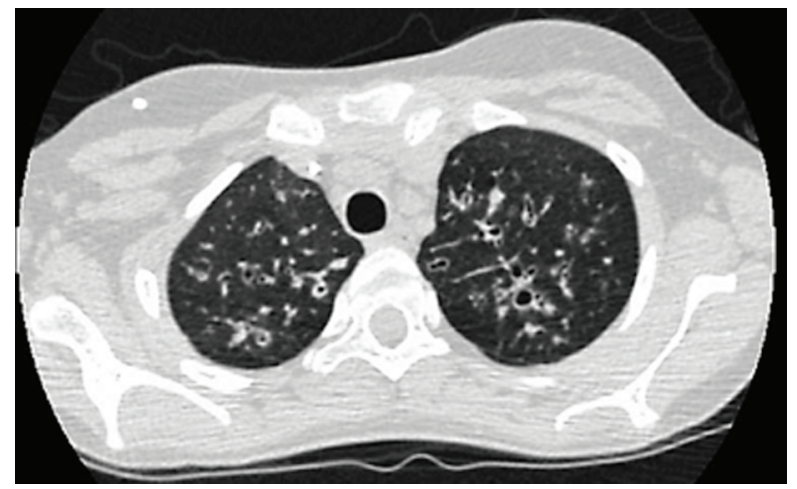

Figure 1 First CT of the chest showing bronchiectasis in both upper lobes.

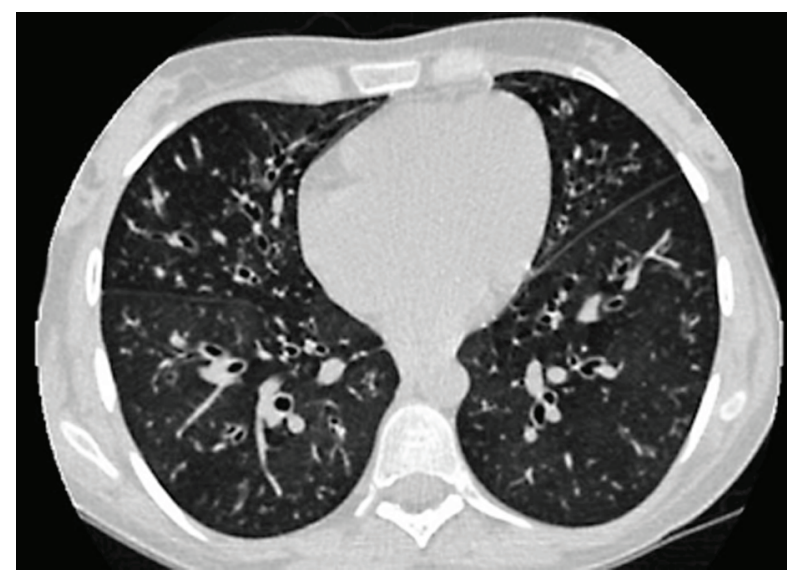

Figure 3 First CT of the chest showing bronchiectasis in both lower zones. aggressive antibiotic treatment and physiotherapy, she remained intermittently feverish, forced expiratory volume exhaled during the first second dropped from $43 \%$ to $22 \%$ of predicted value and inflammatory markers remained raised. Although consolidation had improved on chest $\mathrm{x}$-ray, the bronchiectatic changes had worsened. CT of the chest showed dramatic deterioration in bronchiectasis throughout both lungs compared with CT 6 weeks earlier. Figures 1,2 and 3 are from the first CT of the chest, while figures 4, 5 and 6 are from second scan. Despite aggressive

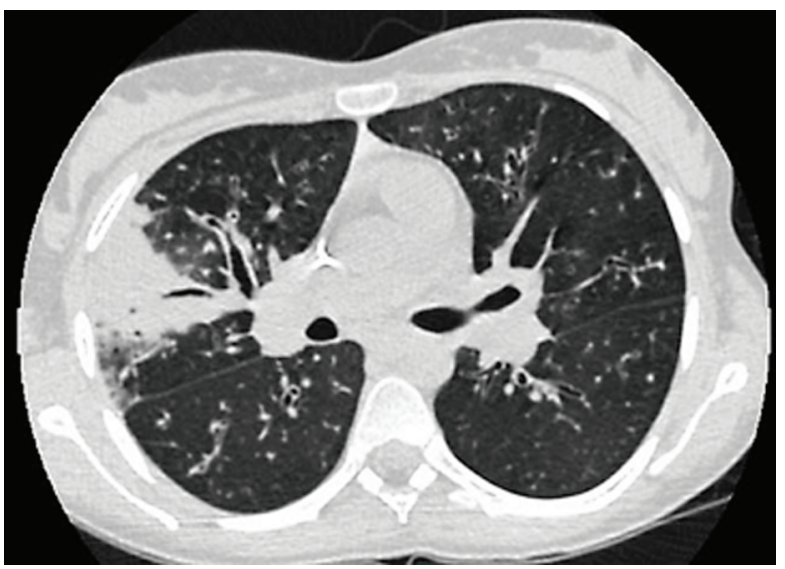

Figure 2 First CT of the chest showing bronchiectasis in mid zones bilaterally and consolidation on right side.

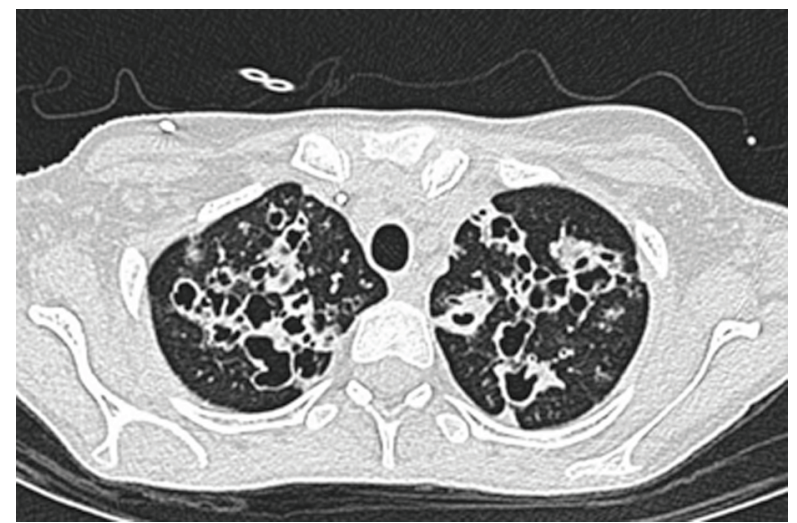

Figure 4 Second CT showing accelerated bronchiectasis in upper zones. 


\section{BMJ Case Reports}

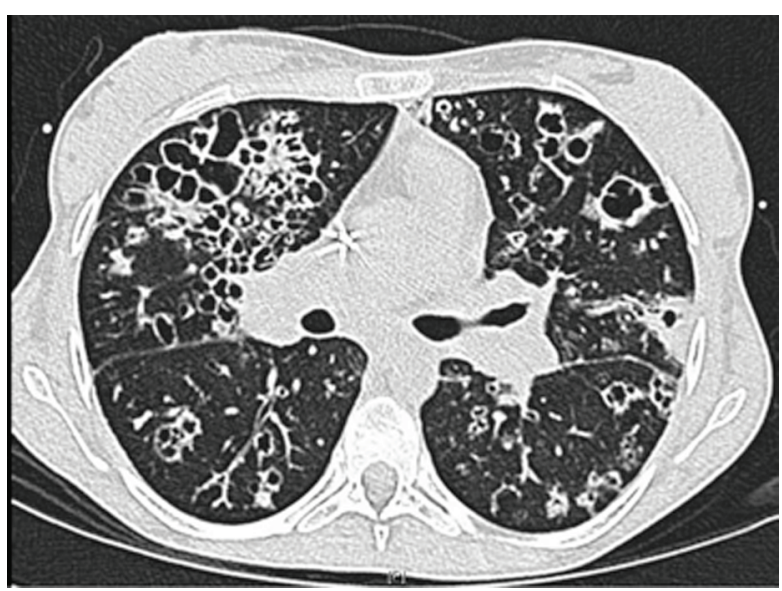

Figure 5 Second CT showing accelerated bronchiectasis in mid zones.

and persistent antibiotic treatments alongside lung clearance therapies and nutritional support, the patient remains unwell and has not managed to regain her lung function.

\section{DISCUSSION}

Burkholderia cepacia complex (BCC) is a group of organisms closely related to pseudomonas species. More than 10 BCC genomovars are known to be pathogenic in cystic fibrosis. Genomovar III (B cenocepacia) is associated with accelerated decline in lung function. Other genomovars are thought to be less aggressive.

Cepacia syndrome is a rapid clinical deterioration in patients with new acquisition of or chronic colonisation with BCC and carries a very high mortality. In chronically

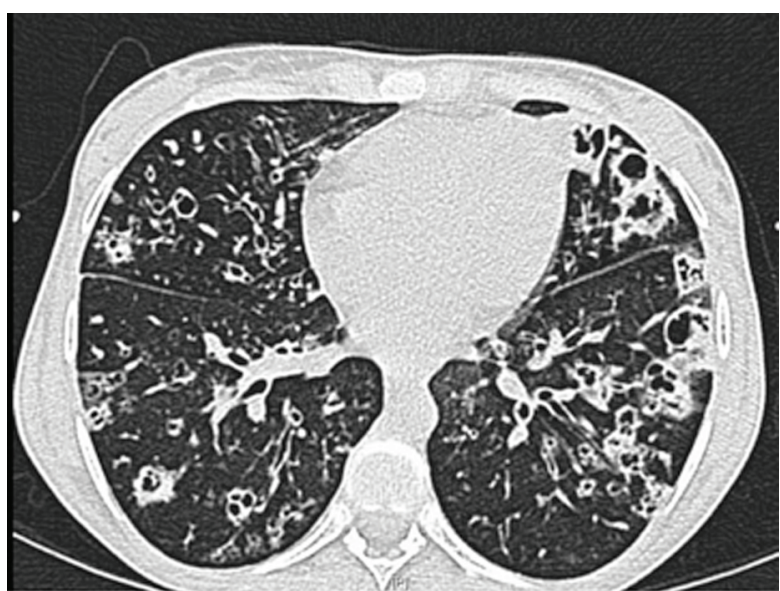

Figure 6 Second CT showing accelerated bronchiectasis in lower zones.

colonised patients, the deterioration is often triggered by an intercurrent illness. It is commonly associated with BCC genomovar III ( $B$ cenocepacia) but can very rarely be associated with $B$ multivorans. To our knowledge, so far there have only been three published cases of cepacia syndrome in association with $B$ multivorans. ${ }^{1}$

\section{Competing interests None.}

Patient consent Obtained.

\section{REFERENCES}

1. Jones AM, Dodd ME, Govan JR, et al. Burkholderia cenocepacia and Burkholderia multivorans: influence on survival in cystic fibrosis. Thorax 2004;59:948-51.

This pdf has been created automatically from the final edited text and images.

Copyright 2011 BMJ Publishing Group. All rights reserved. For permission to reuse any of this content visit http://group.bmj.com/group/rights-licensing/permissions.

BMJ Case Report Fellows may re-use this article for personal use and teaching without any further permission.

Please cite this article as follows (you will need to access the article online to obtain the date of publication).

Shafiq I, Carroll MP, Nightingale JA, Daniels TVW. Cepacia syndrome in a cystic fibrosis patient colonised with Burkholderia multivorans. BMJ Case Reports 2011; 10.1136/bcr.08.2010.3296, date of publication

Become a Fellow of BMJ Case Reports today and you can:

- Submit as many cases as you like

- Enjoy fast sympathetic peer review and rapid publication of accepted articles

- Access all the published articles

- Re-use any of the published material for personal use and teaching without further permission

For information on Institutional Fellowships contact consortiasales@bmjgroup.com

Visit casereports.bmj.com for more articles like this and to become a Fellow 